\title{
106. Über das Blutlipoid bei der Ankylostomiasisanämie, nebst einem Anhang über Blutzucker, Serumeiweiss und die Senkungsgeschwindigkeit der roten Blutzellen bei derselben.
}

\author{
Von Imasato DōNOMAE.
}

Aus. der med. Klinik von Prof. R. INADA, Kaiserl. Universität zu Tokyo.

(Rec. May 20, 1927. Comm. by K. MiURA, M.I.A., June 12, 1927.)

Über Lipoidgehalt des Blutes bei der Ankylostomiasisanämie hat neulich Narita berichtet. Unabhängig davon hatte der Verfasser seit 2 Jahren sowohl über das Blutlipoid, als auch über Blutzucker, Serumeiweiss und die Senkungsgeschwindigkeit der roten Blutzellen bei Ankylostomiasis Untersuchungen angestellt, nicht nur in der Höhe der Anämie, sondern auch durch den ganzen Verlauf bis zur Erholung. Ferner wurde zum Vergleich der Blutbefund bei Normalen und bei chronischen Anämien, hervorgerufen durch andere Ursachen als Ankylostomiasis, studiert.

Alle Ergebnisse sind in der folgenden Tabelle ganz kurz zusammengefasst (der Lipoidquoefficient und die Senkungsgeschwindigkeit der roten Blutzellen ausgelassen).

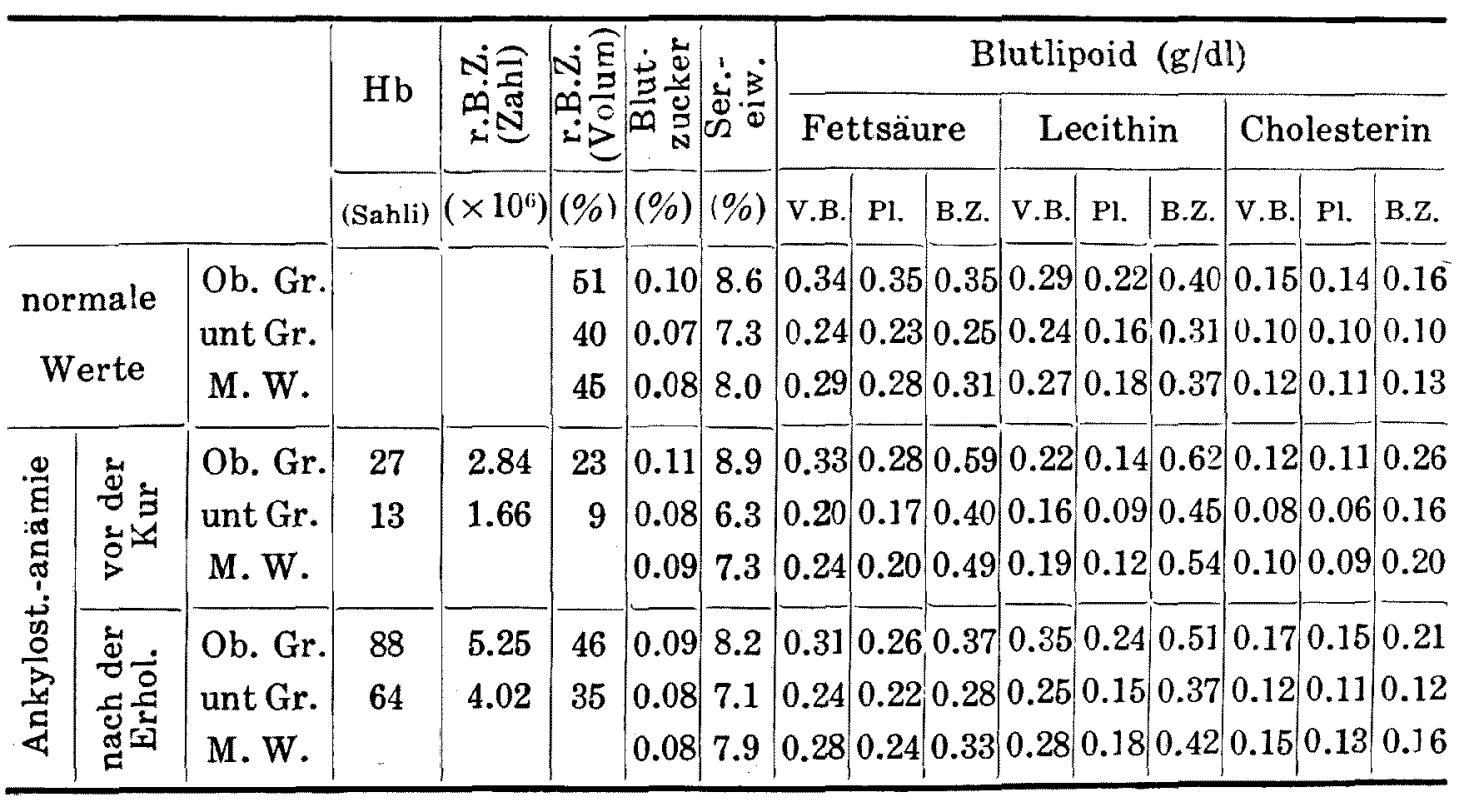


1) Normale Werte.

Bei 20 gesunden Japanern wurden vor der Morgenmahlzeit das Blutlipoid nach Bloor (Neueste Methode!), das Serumeiweiss nach Pulfrich-Reiss und die Senkungsgeschwindigkeit der roten Blutzellen nach Linzenmeier bestimmt.

2) Ankylostomaanämien.

a) Auf dem Höhepunkt der Anämie nahm das Blutlipoid im Serum und Vollblut ab, dagegen in den Blutzellen zu, obgleich der Grad der Veränderung nicht gleich war. Die Abnahme im Plasma und Vollblut war bei Lecithin am deutlichsten und konstant, bei Cholesterin und Fettsäure relativ gering, während die Zunahme in den Blutzellen bei Fettsäure am deulichsten und bei Leithin und Cholesterin relativ gering war. Die Verschiebung des Lipoidspiegels im Blut ging im Allgemeinen mit dem Grad der Anämie parallel, und zwar war dies besonders bei Lecithin der Fall. Von den Lipoidquotienten stieg $\frac{\text { Fettsäure }}{\text { Leicithin }}$ an, während $\frac{\text { Lecithin }}{\text { Cholesterin }}$ unver ändert blieb. Das Verhältniss zwischen dem freien und gebundenen Cholesterin im Plasma war fast dasselbe wie bei Normalen.

Der Blutzucker lag meist in der oberen Grenze der Normalen, das Serumeiweiss nahm bei vielen Fällen ab, während die Senkungsgeschwindigkeit der roten Blutzellen ohne Ausnahme zunahm.

b) Nach Abtreibung der Würmer wurde die Behandlung 2-4 Wochen ausgesetzt und nur beobachtet. In dieser Zeit besserte sich die Anämie in 4 Fällen von 8 etwas und bei denselben 4 Fällen mit Ausnahme eines Falles nahm das Blutlipoid im Plasma zu, während bei den anderen 4 Fällen sowohl der Zustand der Anämie als auch das Blutlipoid unverändert blieb, so dass sich zwischen der Verschiebung des Blutlipoids und der Anämie selbst eine innige Beziehung annehmen lässt.

c) Mit der deutlichen Besserung der Anämie durch Zugabe von Eisenpräparaten, nahm das Blutlipoid ohne Ausnahme im Plasma und Vollblut $\mathrm{zu}$, dagegen in den Blutzellen $\mathrm{ab}$, und erreichte die normale Grenze fast zur gleichen Zeit mit der Zahl und dem Volumprozentsatz der roten Blutzellen. Dabei nahm das Cholesterin im Plasma am deutlichsten und schnellsten $z u$, und zeigte manchmal eine deutliche Hypercholesterinämie, während die Zunahme bei Lecithin weniger schnell und bei Fettsäure am langsamstan war. Der Lipoidquotient Fettsäure Leicithin , welcher im anämischen Stadium abnorm gross war, stieg 
mit der Besserung allmählich ab. Auf Grund dieser Tatsache scheint die Vermutung Bloors, dass die roten Blutzellen in Bezug auf das Gleichgewicht zwischen der Fettsäure und dem Leicthin gewisse Rolle spielen, eine neue Stütze zu bekommen.

Der Blutzucker stieg bei einigen Fällen mit der Besserung der . Anämie von der oberen Grenze nach dem normalen Mittelwert ab, das Serumeiweiss nahm bei den meisten Fällen zu und die Senkungsgeschwindigkeit der roten Blutzellen bei allen Fällen ab.

3) Chronische Anämien auf Grund anderer Ursachen.

Um zu wissen, ob der Befund bei Ankylostomaanämie dieser Krankheit specifisch sei oder nicht, wurde 4 chronische Anämien anderer Ursachen untersucht (Aplastische Anämie 1 Fall, senkundäre Anämie infolge von Magenkrebs 2 Fälle, sekundäer Anämie infolge wiederholter Nasenblutung 1 Fall). Die Resultate in Bezug auf die obenbehandelten vier Komponenten und die gegenseitigen Beziehungen derselben zu einander zeigten fast dieselben Verhältnisse wie bei Ankylostomaanämie, und wurde kein wesentlicher Unterschied zwischen beiden gefunden.

Aus diesen Ergebnissen möchte der Verfasser schliessen, dass die Veränderung im Gehalt des Blutlipoides bei Ankylostomaanämie höchstwahrscheinlich ein sekundäres Ereigniss der chronischen Anämie selbst ist und die Abweichung des Lipoidgshalts im Blut nicht als Ursache der Anämie betrachtet werden kann. 